\title{
The use of reverse transcription-PCR for the diagnosis of $X$-linked chronic granulomatous disease
}

\section{P. Agudelo-Flórez ${ }^{1}$, \\ J.A. López ${ }^{1}$, \\ J. Redher ${ }^{1}$,}

M.M.S. Carneiro-Sampaio ${ }^{2}$, B.T. Costa-Carvalho ${ }^{3}$,

A.S. Grumach ${ }^{4}$ and A. Condino-Neto ${ }^{1}$
Correspondence

A. Condino-Neto

Centro de Investigação em Pediatria FCM, UNICAMP

Caixa Postal 6111

13081-970 Campinas, SP

Brasil

Fax: +55-19-3289-8638

E-mail: condino@lexxa.com.br or

condino@unicamp.br

Research supported by FAPESP (Nos. 01/14365-3, 01/14365-3 and 02/05880-4), CNPq (No. 470413/034), CAPES, and The United States National Institutes of Health Fogarty International Center (No. 1RO3TW00883-01). .....................

Received February 5, 2003 Accepted February 10, 2004

\author{
${ }^{1}$ Centro de Investigação em Pediatria e Departamentos de Pediatria e Farmacologia, \\ Faculdade de Ciências Médicas, Universidade Estadual de Campinas, Campinas, SP, \\ Brasil \\ ${ }^{2}$ Departamento de Imunologia, Instituto de Ciências Biomédicas, \\ Universidade de São Paulo, São Paulo, SP, Brasil \\ ${ }^{3}$ Disciplina de Alergia, Imunologia e Reumatologia, Departamento de Pediatria, \\ Escola Paulista de Medicina, Universidade Federal de São Paulo, São Paulo, SP, Brasil \\ ${ }^{4}$ Laboratório de Investigação Médica 56, Departamento de Dermatologia, \\ Faculdade de Medicina, Universidade de São Paulo, São Paulo, SP, Brasil
}

\section{Abstract}

Chronic granulomatous disease (CGD) is an inherited disorder of the innate immune system characterized by a defective oxidative burst of phagocytes and subsequent impairment of their microbicidal activity. Mutations in one of the NADPH-oxidase components affect gene expression or function of this system, leading to the phenotype of CGD. Defects in gp91-phox lead to X-linked CGD, responsible for approximately $70 \%$ of CGD cases. Investigation of the highly heterogeneous genotype of CGD patients includes mutation analysis, Northern blot or Western blot assays according to the particular case. The aim of the present study was to use reverse transcription (RT)-PCR for the analysis of molecular defects responsible for X-linked CGD in eight Brazilian patients and to assess its potential for broader application to molecular screening in CGD. Total RNA was prepared from Epstein B virus-transformed B-lymphocytes and reverse transcribed using random hexamers. The resulting cDNA was PCR-amplified by specific and overlapping pairs of primers designed to amplify three regions of the gp91-phox gene: exons 1-5, 3-9, and 7-13. This strategy detected defective gp91-phox expression in seven patients. The RTPCR results matched clinical history, biochemical data (nitroblue tetrazolium or superoxide release assay) and available mutation analysis in four cases. In three additional cases, RT-PCR results matched clinical history and biochemical data. In another case, RT-PCR was normal despite a clinical history compatible with CGD and defective respiratory burst. We conclude that this new application of RT-PCR analysis - a simple, economical and rapid method - was appropriate for screening molecular defects in 7 of 8 X-linked CGD patients.
Key words - Superoxide - Phagocytes - Primary immunodeficiency - Respiratory burst

- Neutrophils

- Human $\ldots \ldots \ldots \ldots \ldots \ldots \ldots$ 


\section{Introduction}

Chronic granulomatous disease (CGD) is a primary immunodeficiency originally described in 1957 as a clinical entity affecting male infants and named, at the time, fatal granulomatous disease of childhood. The main characteristics of CGD are recurrent and severe infections involving the natural barriers of the organism such as the respiratory tract and lymph nodes, and eventually inner structures such as the liver, spleen, bones, and brain (1-3). The estimated incidence of this rare disease is $1 / 250,000$ live births per year. The infections are generally caused by catalase-negative bacteria such as Staphylococcus aureus, Gram-negative bacilli, and fungal species such as Aspergillus, Candida and Nocardia $(4,5)$.

The NADPH-oxidase system generates superoxide and other reactive oxygen intermediates, crucial for the microbicidal activity of phagocytes. The biochemical defect in CGD is an impairment of NADPH-oxidase activity and subsequent inability to destroy microorganisms (6). The main components of the NADPH-oxidase system are gp91-, p22-, p47-, p67-, and p40-phox. Molecular defects causing CGD are generally due to absence, low expression or malfunctioning of one of the NADPH-oxidase components. The X-linked form of this disease is caused by defects in gp91-phox, the heavy chain of cytochrome $\mathrm{b}_{588}$, and accounts for approximately $70 \%$ of all cases $(7,8)$. The autosomal recessive forms are caused by defects in one of the cytosolic components of NADPH oxidase (p47- or p67-phox, respectively in 20 and $5 \%$ of cases), or the cytochrome $b_{588}$ light chain component (p22-phox, 5\% of cases) $(9,10)$. CGD is a highly heterogeneous condition: over 300 mutations have been registered in an internationally maintained X-CGD database (8). The mutations have been distributed largely within the 13 exons or at the exon/intron boundaries of the gp91-phox (CYBB) gene and almost 200 of these mutations are unique.

The diagnosis of CGD is generally based on the clinical characteristics of the disease plus defective NADPH-oxidase activity as demonstrated by abnormal nitroblue tetrazolium (NBT), dihydrorhodamine 123, or superoxide release assays $(11,12)$. In the stimulated NBT test, normal individuals display nearly $100 \%$ positive cells, while in CGD patients fewer than 5\% of the cells are positive (13). In addition, cells from patients with variant CGD are positive, but show only very low activity (6). The NBT test also detects the carriers of X-linked CGD (mothers and sisters). A definitive molecular CGD diagnosis is established in patients with an abnormal NBT test or respiratory burst activity who have one of the following characteristics: a mutation in gp91-, p22-, p47-, or p67-phox; absent mRNA for one of these genes detected by Northern blot analysis; and/or absent protein for one of these oxidase components by Western blot. A genetic, but not molecular, diagnosis can be established by demonstration of maternal cousins, uncles, or nephews with an abnormal NBT test or respiratory burst (14). Thus, the establishment of a definitive diagnosis of this rare and highly heterogeneous disease requires complex and expensive methodologies such as a combination of Northern blot or Western blot, and single-strand conformation polymorphism analysis (SSCP) followed by DNA sequencing of several family members, all performed in high complexity research laboratories.

The reverse transcription-PCR (RT-PCR) method involves the amplification of cDNA by PCR. This technique can be easily standardized in less sophisticated laboratories. It provides information about gene expression and preliminary data about the structure or size of the mRNA of the defective component. RT-PCR has seldom been used in CGD research, being limited to pathophysiology studies (15-29). To date, the potential use of this useful tool for establishing the definitive 
diagnosis of X-linked CGD, the most frequent form, has not been extensively investigated. The aim of the present study was to evaluate the use of RT-PCR for screening molecular defects responsible for X-linked CGD, a rare and possibly misdiagnosed immunodeficiency, in eight Brazilian patients.

\section{Patients and Methods}

\section{Patients}

The study included 8 unrelated male Brazilian patients with probable X-linked CGD (2 Blacks and 6 Caucasians; age 2-8 years; height $88-108 \mathrm{~cm}$; weight $11-19 \mathrm{~kg}$ ). The patients presented clinical histories of recurrent severe infections such as pneumonia, lymphadenitis, liver abscess, pyodermitis, and adverse reactions to BCG immunization. They were referred to our laboratory for biochemical and molecular diagnostic evaluation. Written informed consent was obtained from the participants prior to the study. The Medical School Ethics Committee approved the protocol in accordance to the Helsinki Convention and Brazil Ministry of Health, Resolution 196/96.

\section{Biochemical diagnosis of CGD}

The biochemical diagnosis of CGD was established according to the Pan American Group for Immunodeficiencies criteria. An impairment of NADPH-oxidase activity was demonstrated by the NBT slide test and/or the superoxide anion release assay by peripheral blood neutrophils and mononuclear leukocytes $(14,30,31)$. Neutrophils and mononuclear leukocytes were obtained by centrifugation of blood samples over a FicollHypaque density gradient (32).

The NBT slide test was based on the reduction of NBT to formazan by activated leukocytes (31). The assay was performed as previously described (30). More than 95\% of 200 normal neutrophils stimulated with
$30 \mathrm{nM}$ phorbol 12-myristate 13-acetate (PMA) should be able to reduce NBT. Absent reaction or $<5 \%$ positive cells was considered to indicate a diagnosis of CGD (14).

Quantitative superoxide release by neutrophils and mononuclear leukocytes was assessed by a modified superoxide dismutase-inhibitable cytochrome c reduction assay (33-35). The amount of superoxide released was calculated using an extinction coefficient of $0.21 \mathrm{nM} / \mathrm{cm}$ for cytochrome c. The results are reported as nmol superoxide released by $10^{6}$ cells per hour. Patients with CGD showed less than $10 \%$ of control values.

\section{Screening molecular defects responsible for X-linked CGD}

B-lymphocytes from X-linked CGD patients were transformed in vitro with Epstein $B$ virus (EBV) $(15,16)$ in order to provide an abundant source of nucleic acids for molecular studies. The EBV-transformed B cell lines reproduce the biochemical and molecular defects of CGD patients $(15,16,36)$, and eliminate the need for repeated blood collections. Briefly, peripheral blood leukocytes from X-linked CGD patients were cultured with supernatants from B95-8, an EBV-producer cell line $(15,16,36,37)$, in RPMI 1640 medium supplemented with heat-inactivated fetal bovine serum (10\%), 2 mM L-glutamine, $100 \mathrm{U} / \mathrm{ml}$ penicillin, and $100 \mu \mathrm{g} / \mathrm{ml}$ of streptomycin, at $37^{\circ} \mathrm{C}$, in a humid atmosphere with $5 \% \mathrm{CO}_{2}$. Cell viability was monitored and the cultures were maintained throughout the study period.

RNA samples from EBV-transformed Bcell lines were prepared by the guanidine $\mathrm{HCl}$ method, followed by ethanol precipitation and quantification by standard methods $(38,39)$. The cDNA samples were obtained by reverse transcription of $2 \mu \mathrm{g}$ of total RNA with SuperScript II RT (GIBCO BRL) and random hexamers (15). The quality of the mRNA samples was checked by PCR amplification of $\beta$-actin, a constitutive gene con- 
trol (bp 920-943 and bp 1494-1471) (Gen Bank accession No. NM001101).

gp91-phox gene expression was assessed by RT-PCR. Specific and overlapping pairs of primers (Gen Bank accession No. NM_000397, Table 1) were used to amplify (30 cycles) three gp91-phox exonic regions: $1-5,3-9$, and $7-13$. This strategy permitted us to screen all gp91-phox exons. PCR products were analyzed by $2 \%$ agarose gel elec- trophoresis and stained with ethidium bromide.

Relative gp91-phox gene expression was analyzed with the Image Master Software (Pharmacia-Biotech). The densitometry result for target samples was divided by the densitometry result of $\beta$-actin, a constitutive gene control, normalizing the level considered for analysis. The results of RT-PCR assays were compared to patient clinical his-

Table 1. Oligonucleotide primers used for gp91-phox RT-PCR analysis.

\begin{tabular}{lll}
\hline \multirow{2}{*}{ Region } & \multicolumn{2}{c}{ Sequence of gp91-phox primers } \\
\cline { 2 - 3 } & \multicolumn{2}{c}{ Rorward } \\
\hline Exons 1-5 & 5'-GCT CTA GAG CAT GAG GGG CTC & \multicolumn{1}{c}{ 5'-CGG GAT CCC GAG TTC AGA GAG } \\
& TCC ATT TTT GTC A-3' & TGC TAC TGA ATA A-3' \\
Exons 3-9 & 5'-GCC TGC CTG AAT TTC AAC-3' & 5'-TCA TCT GTA GCT CGA TG-3' \\
Exons 7-13 & 5'-GGA ATG CCC AAT CCC TCA G-3' & 5'-GGG CCA GAC TCA GAG TTG G-3'
\end{tabular}

Table 2. Stimulated respiratory burst activity of granulocytes (GRA) and mononuclear leukocytes (MON) as assessed by the nitroblue tetrazolium (NBT) test or superoxide release assay, and gp91-phox gene expression in Epstein B virus-transformed B lymphocytes from patients with chronic granulomatous disease as assessed by RT-PCR analysis.

\begin{tabular}{|c|c|c|c|c|c|}
\hline \multirow[t]{2}{*}{ Patient } & \multicolumn{2}{|c|}{ Respiratory burst activity } & \multicolumn{3}{|c|}{ Relative gp91-phox expression } \\
\hline & NBT & Superoxide & Exons $1-5$ & Exons 3-9 & Exons 7-13 \\
\hline 1. G.M. & & MON 1.0 & Reduced & Reduced & Absent \\
\hline 2. R.B. & $<5 \%$ & & Reduced & Reduced & Reduced \\
\hline 3. G.G. & $<5 \%$ & & Possible splicing defect & Absent & Absent \\
\hline 4. T.P.B. & $<5 \%$ & $\begin{array}{l}\text { MON } 0.27 \\
\text { GRA } 0.22\end{array}$ & Normal expression & Normal expression & Normal expression \\
\hline 5. M.F. & $<5 \%$ & GRA 0.22 & Normal expression & Reduced & Reduced \\
\hline 6. T.P. & $<5 \%$ & $\begin{array}{l}\text { MON } 0.25 \\
\text { GRA } 0.46\end{array}$ & Normal expression & Reduced & Absent \\
\hline 7. R.S. & & $\begin{array}{l}\text { MON }-0.03 \\
\text { GRA } 0.58\end{array}$ & Possible splicing defect & Absent & Reduced \\
\hline 8. J.E.M. & $<5 \%$ & $\begin{array}{l}\text { MON } 0.0 \\
\text { GRA } 0.3\end{array}$ & Absent & Absent & Absent \\
\hline
\end{tabular}

NBT is reported as percent of positive cells. Normal individuals display nearly $100 \%$ positive cells. GRA and MON from healthy controls released superoxide in the range of 6-14 and 5-7 nmol $\mathrm{O}_{2}^{-1} 0^{6} \mathrm{cells}^{-1} 60 \mathrm{~min}^{-1}$, respectively. 
tory, biochemical assays (NBT and/or superoxide release assay), and available mutation analysis data (http://www.sbi.org.br/Sbi2003/ index.htm).

\section{Results}

We studied 8 male patients with clinical histories of recurrent severe infections, referred to our laboratory for biochemical and molecular diagnosis of CGD. The results of the NBT slide tests and the superoxide release assays are shown in Table 2. Six of the patients presented less than $5 \%$ positive leukocytes in the NBT slide test. Six patients showed impaired superoxide release by granulocytes and/or mononuclear leukocytes (less than 10\% compared to healthy controls). Four patients had abnormal results in both tests. All patients presented at least one abnormal test and received the diagnosis of probable X-linked CGD. The mother and the sister of patient T.B.P. presented an NBT slide test compatible with the carrier status of X-linked CGD. During the study period one patient (G.M.) died from pneumonia.

We next investigated the definitive diagnosis of X-linked CGD by RT-PCR analysis of gp91-phox gene expression. The results of RT-PCR amplification with three sets of overlapping primers are presented in Table 2. The quality of the mRNA sample was checked by PCR amplification of $\beta$-actin, a constitutive gene control. The expected normal products were obtained in this case (Figures 1, 2 and 3).

The amplification of exons 1-5 detected two patients (G.M. and R.B.) with reduced gp91-phox gene expression (Figure 1, lanes 1 and 2, respectively). One patient (J.E.M., lane 8) showed absent gp91-phox gene expression. Two patients (G.G. and R.S.; Figure 1 , lanes 3 and 7 , respectively) presented a smaller PCR product (between 300 and $400 \mathrm{bp}$ ), suggesting a splicing defect or small deletion. Three patients presented normal gp91-phox expression (T.P.B., M.F. and T.P.; Figure 1, lanes 4, 5, and 6, respectively).

The results of RT-PCR amplification of gp91-phox exons 3-9 are presented in Figure

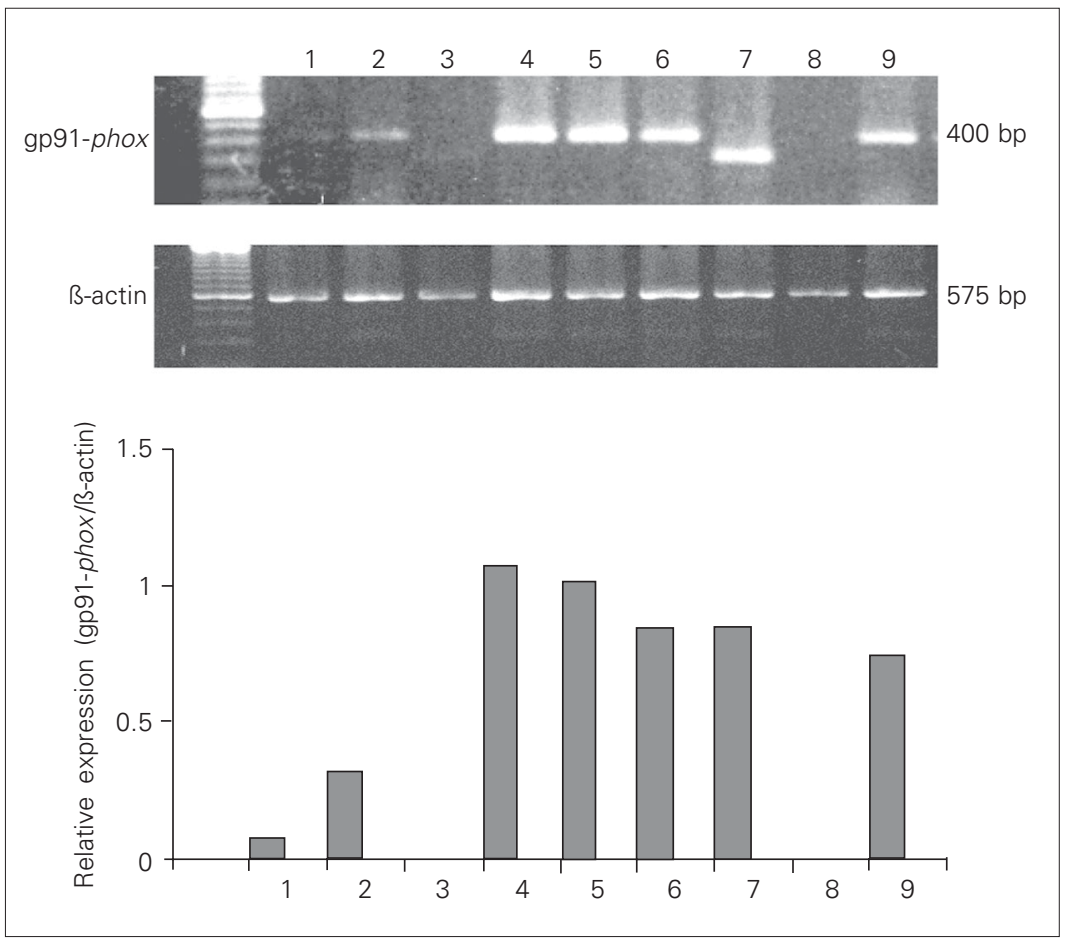

Figure 1. RT-PCR analysis of gp91-phox gene expression (exons 1-5) in Epstein B virus-transformed B cells from patients with $X$-linked chronic granulomatous disease. Representative $2 \%$ agarose gel electrophoresis of PCR products stained with ethidium bromide. Size standards (100-bp ladder); Lane 1, patient G.M.; lane 2, patient R.B.; lane 3, patient G.G.; lane 4, patient T.P.B.; lane 5, patient M.F.; lane 6, patient T.P.; lane 7, patient R.S.; lane 8, patient J.E.M., and lane 9, healthy control. ß-actin was used as an internal control for RT-PCR in all samples. The lower panel shows the mean band densitometry of gp91-phox/ß-actin relative expression $(\mathrm{N}=$ 3). 
Figure 2. RT-PCR analysis of gp91-phox gene expression (exons 3-9) in Epstein B virus-transformed B cell lines from patients with X-linked chronic granulomatous disease. Representative $2 \%$ agarose gel electrophoresis of PCR products stained with ethidium bromide. Size standards (100-bp ladder); Lane 1, patient G.M.; lane 2, patient R.B.; lane 3, patient G.G.; lane 4, patient T.P.B.; lane 5, patient M.F.; lane 6, patient T.P.; lane 7, patient R.S.; lane 8, patient J.E.M., and lane 9, healthy control. ß-actin was used as an internal control for RT-PCR in all samples. The lower panel shows the mean band densitometry of gp91-phox/ß-actin relative expression $(\mathrm{N}=3)$.
Figure 3. RT-PCR analysis of gp91-phox gene expression (exons 7-13) in Epstein B virustransformed $B$ cell lines from X-linked CGD patients. Representative $2 \%$ agarose gel electrophoresis of PCR products stained with ethidium bromide. Size standards (100-bp ladder); Lane 1, patient G.M.; lane 2, patient R.B.; lane 3, patient G.G.; lane 4, patient T.P.B.; lane 5, patient M.F.; lane 6, patient T.P.; lane 7, patient R.S.; lane 8, patient J.E.M., and lane 9, healthy control. ß-actin was used as an internal control for RT-PCR in all samples. The lower panel shows the mean band densitometry of gp91phox/ß-actin relative expression ( $N=3$ ).
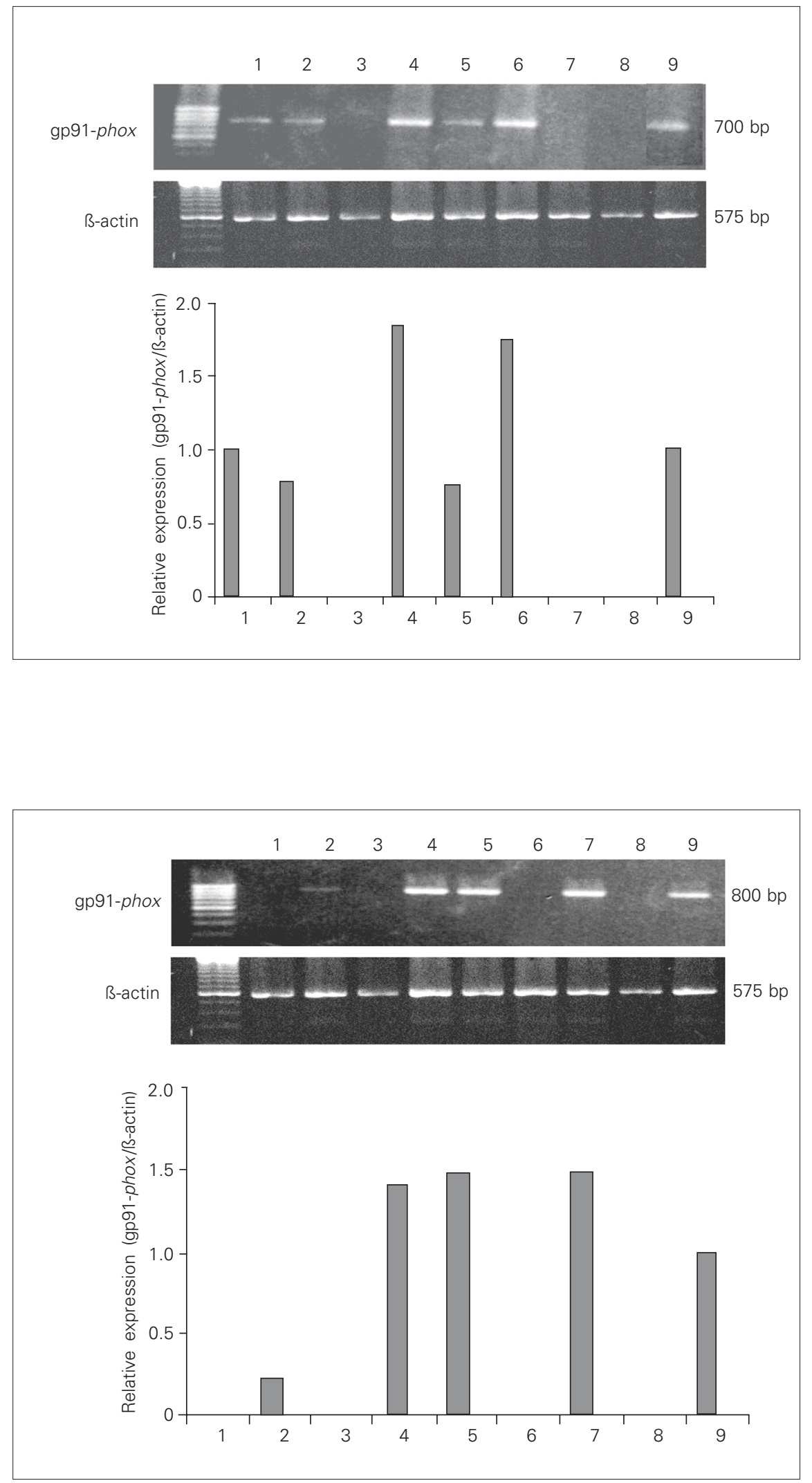
2. Two patients (R.B. and M.F.) presented reduced gp91-phox gene expression (Figure 2, lanes 2 and 5, respectively). Three patients (G.G., R.S., and J.E.M.; lanes 3, 7, and 8 , respectively) presented absent gp91-phox gene expression. Three patients presented normal gp91-phox expression (G.M., T.P.B. and T.P.; Figure 2, lanes 1, 4 and 6, respectively).

RT-PCR amplification of gp91-phox exons 7-13 is presented in Figure 3. One patient (R.B.) presented reduced gp91-phox gene expression (Figure 3, lane 2). Four patients (G.M., G.G., T.P. and J.E.M., lanes $1,3,6$, and 8 , respectively) presented absent gp91-phox gene expression. Three patients (T.P.B., M.F. and R.S.; Figure 3, lanes 4, 5 and 7, respectively) presented normal gp91phox expression.

In four cases, it was possible to match RT-PCR data with available mutation analysis, presented elsewhere by Patiño et al. (30) or by our group (http: //www.sbi.org.br/ Sbi2003/index.htm): J.E.M. presented a $\mathrm{C}_{469} \rightarrow \mathrm{T}$ transition in exon 5, predicting a nonsense mutation (R157X). M.F. presented a nonsense substitution in exon 3, R (arginine) 73-Stop. R.S. showed a $264 \mathrm{G} \rightarrow \mathrm{A}$ substitution at the 3 ' splice junction of gp91phox exon 3. The cDNA sequence showed a deletion of gp91-phox exon 3, giving rise to an unstable or nonfunctional mutant gp91phox. G.G. presented a defective splicing of gp91-phox exon 3 (the underlying mutation has not yet been determined). The other patients continue to be under investigation.

As a whole, this strategy permitted the detection of defective gp91-phox expression in seven of eight patients. The RT-PCR results matched clinical history, biochemical data (NBT or superoxide release assay) and available mutation analysis in four cases. In three additional cases, RT-PCR results matched clinical history and biochemical data. In another case, RT-PCR was normal despite a clinical history compatible with CGD, a defective respiratory burst charac- terized by the NBT test and superoxide release assay and NBT tests of his mother and sister compatible with X-linked CGD carrier status.

\section{Discussion}

This paper reports on the biochemical and gene expression studies of 8 unrelated Brazilian male patients with a clinical history of CGD, who were referred to our laboratory for detailed investigation. CGD is a rare inherited disorder in which phagocytic cells are unable to generate superoxide anion and other reactive oxygen intermediates. We initially established the diagnosis of probable X-linked CGD by means of biochemical methods such as the NBT slide tests and/ or superoxide anion release assays. Our results showed that all patients presented impaired NADPH-oxidase function and, in turn, probable X-linked CGD.

Both methods contribute to the probable diagnosis of CGD in different ways. The NBT slide test provides information about the number of cells that reduce NBT to formazan inside the cytoplasm and the intensity of this reduction. Thus, patients with variant forms of $\mathrm{X}$-linked CGD show abnormal NBT slide tests, in which most of the cells weakly reduce NBT to formazan. The NBT slide test also detects female carriers of $\mathrm{X}$-linked CGD. The superoxide release assay measures the reduction of cytochrome $\mathrm{c}$ by superoxide produced by activated leukocytes present in the reaction, permitting the diagnosis of variant forms of X-linked CGD. Both tests can be easily standardized in low complexity laboratories and neither requires expensive equipment. The dihydrorhodamine 123 test is a highly sensitive method for the biochemical diagnosis of CGD; however, it requires a flow cytometer, a very expensive instrument.

We evaluated gp91-phox gene expression in EBV-transformed B lymphocytes from CGD patients by RT-PCR analysis. 
Specific and overlapping pairs of primers were used to amplify three regions of the gp91-phox gene by RT-PCR: exons 1-5, 3-9, and 7-13. This strategy permitted the detection of defective gp91-phox expression in 7 of 8 patients. The RT-PCR results matched clinical history, biochemical data (NBT or superoxide release assay) and available mutation analysis in four cases. In three additional cases, RT-PCR results matched clinical history and biochemical data.

gp91-phox gene expression was reduced in all exonic regions of patient R.B. This reduction can be the result of mutations leading to low RNA stability or altered transcriptional activity. Patients G.M. and T.P. showed absent expression of exons 7-13, suggesting that the decreased expression of these additional 3'-end exons can be the result of RNA instability or a splicing defect, e.g., partially correct splicing to produce a signal, but partially abnormal splicing to eliminate a primer binding site, a subject to be investigated by future genomic DNA mutation analyses.

Patient G.G. presented a diffuse, low abundance, smaller-sized product of exons 1-5 (Figure 1), and absent expression of other exonic regions. His mutation analysis showed a defect at the exon 3 splice site. Similarly, the mutation analysis of patient R.S. also revealed a defect at the exon 3 splice site. However, in this case, a less abundant PCR product could be detected.

Patient M.F. presented reduced expression of exonic regions 3-9 and 7-13, which can be the result of defective transcriptional activity in exon 3. J.E.M. presented a nonsense mutation in exon 5 that resulted in loss of gp91-phox expression, as evidenced by RT-PCR analysis, a possible consequence of nonsense-mediated mRNA instability.

In one case, patient T.P.B., gp91-phox gene expression was normal despite a family history compatible with CGD and a defective respiratory burst activity. In this case, the diagnosis of probable X-linked CGD was based on abnormal NBT tests in his mother and his sister, compatible with carrier status. We hypothesize that a point mutation, such as a single base substitution that does not change PCR fragment length or abundance, should be investigated in this particular case.

RT-PCR is a powerful tool to assess gene expression. This characteristic may partially explain the variability of gp91-phox gene expression among the patients included in this study, and the importance to combine overlapping pair of primers to screen the full length of the message. RT-PCR has been used in isolated case studies as part of the initial diagnosis of the different forms of CGD (17-22). RTPCR analysis was also useful in the prenatal diagnosis of CGD, resulting from p47-phox deficiency (23). However, it has been more commonly used for the study of gene regulation of the NADPH-oxidase components in a variety of cells $(15,16,24-29)$. To date, the potential use of this useful tool for establishing the definitive diagnosis of X-linked CGD, the most frequent form, has not been investigated extensively. Further studies should be performed to compare the sensitivity and specificity of this test compared to other complex assays such as Western or Northern blots.

Overall, we have demonstrated that RTPCR, a simple and low cost methodology, established the definitive diagnosis of $\mathrm{X}$ linked CGD in 7 of 8 cases, without the need to use complex and expensive methodologies such as Northern blot, slot blot, SSCP analysis, or genomic DNA sequencing. Thus, RT-PCR may be a suitable tool for diagnosing CGD in laboratories in developing countries. It is very important to determine the definitive molecular genetic defect in order to provide the appropriate genetic counseling and prognosis to kindreds with CGD. In addition, molecular genetic studies of the human NADPH-oxidase system will advance the knowledge about this crucial and ancient defense mechanism. 


\section{Acknowledgments}

The authors thank the patients and their families for participating and for their help, and the nurse Silvana Severino for technical assistance. The authors also thank Prof. Peter Newburger, University of Massachusetts Medical School, for a critical review of this manuscript.

\section{References}

1. Berendes H, Bridges RA \& Good RA (1957). A fatal granulomatosus of childhood: the clinical study of a new syndrome. Minnesota Medicine, 40: 309-312.

2. Landing BH \& Shirkey HS (1957). A syndrome of recurrent infection and infiltration of the viscera by pigmented lipid histiocytes. Pediatrics, 20: 431-442.

3. Patterson EL, Milstrey R \& Stokstad ELR (1975). Effect of selenium in preventing exudative diathesis in chicks. Proceedings of the Society for Experimental Biology and Medicine, 95: 617-620.

4. Tauber Al, Borregaard N, Simons ER \& Wright J (1983). Chronic granulomatous disease A syndrome of phagocyte oxidase deficiencies. Medicine, 62: 286-309.

5. Forrest $C B$, Forehand JR, Axtell RA, Roberts RL \& Johnston Jr RB (1988). Clinical features and current management of chronic granulomatous disease. Hematology/Oncology Clinics of North America, 2: 253-266.

6. Curnutte JT (1993). Chronic granulomatous disease: the solving of a clinical riddle at the molecular level. Clinical Immunology and Immunopathology, 67: S2-S15.

7. Dinauer MC, Orkin SH, Brown R, Jesaitis AJ \& Parkos CA (1987). The glycoprotein encoded by the $\mathrm{X}$-linked chronic granulomatous disease locus is a component of the neutrophil cytochrome b complex. Nature, 327: 717-720.

8. Heyworth PG, Curnutte JT, Rae J, Noack D, Roos D, van Koppen E \& Cross AR (2001). Hematologically important mutations: X-linked chronic granulomatous disease (second update). Blood Cells, Molecules and Diseases, 27: 16-26.

9. Clark RA, Malech HL, Gallin JI, Nunoi H, Volpp BD, Pearson DW, Nauseef WM \& Curnutte JT (1989). Genetic variants of chronic granulomatous disease: Prevalence of deficiencies of two cytosolic components of the NADPH oxidase system. New England Journal of Medicine, 321: 647-652.

10. Cross AR, Noack D, Rae J, Curnutte JT \& Heyworth PG (2000). Hematologically important mutations: the autosomal recessive forms of chronic granulomatous disease (first update). Blood Cells, Molecules and Diseases, 26: 561-565.

11. Smith RM \& Curnutte JT (1991). Molecular basis of chronic granulomatous disease. Blood, 77: 673-686.

12. Vowells SJ, Fleisher TA, Sekhsaria S, Alling DW, Maguire TE \& Malech HL (1996). Genotype-dependent variability in flow cytometric evaluation of reduced nicotinamide adenine dinucleotide phosphate oxidase function in patients with chronic granulomatous disease. Journal of Pediatrics, 128: 104-107.

13. Roos D, de Boer M, Kuribayashi F et al. (1996). Mutations in the Xlinked and autosomal recessive forms of chronic granulomatous disease. Blood, 87: 1663-1681.

14. Conley ME, Notarangelo LD \& Etzioni A (1999). Diagnostic criteria for primary immunodeficiencies. Clinical Immunology, 93: 190-197.

15. Condino-Neto A \& Newburger PE (1998). NADPH oxidase activity and cytochrome b558 content of human Epstein-Barr virus transformed B lymphocytes correlate with expression of genes encoding components of the oxidase system. Archives of Biochemistry and Biophysics, 360: 158-164.

16. Condino-Neto A \& Newburger PE (2000). Interferon-gamma improves splicing efficiency of CYBB gene transcripts in an interferonresponsive variant of $\mathrm{X}$-linked chronic granulomatous disease due to a splice site consensus region mutation. Blood, 95: 3548-3554.

17. Aoshima M, Nunoi H, Shimazu M, Shimizu S, Tatsuzawa O, Kenney RT \& Kanegasaki S (1996). Two-exon skipping due to a point mutation in p67-phox-deficient chronic granulomatous disease. Blood, 88: $1841-1845$.

18. Azuma $H$ (1994). DNA analysis of cytochrome b positive chronic granulomatous disease (a case report). Rinsho Byori, 42: 242-248.

19. Bonizzato A, Russo MP, Donini M \& Dusi S (1997). Identification of a double mutation (D160V-K161E) in the p67phox gene of a chronic granulomatous disease patient. Biochemical and Biophysical Research Communications, 231: 861-863.

20. Borgato L, Bonizzato A, Lunardi C, Dusi S, Andrioli G, Scarperi A \& Corrocher R (2001). A 1.1-kb duplication in the p67-phox gene causes chronic granulomatous disease. Human Genetics, 108: 504510.

21. Noack D, Heyworth PG, Newburger PE \& Cross AR (2001). An unusual intronic mutation in the CYBB gene giving rise to chronic granulomatous disease. Biochimica et Biophysica Acta, 1537: 125131.

22. Roesler J, Curnutte JT, Rae J, Barrett D, Patino P, Chanock SJ \& Goerlach A (2000). Recombination events between the p47-phox gene and its highly homologous pseudogenes are the main cause of autosomal recessive chronic granulomatous disease. Blood, 95: 2150-2156.

23. De Boer $M$, Singh $V$, Dekker J, Di Rocco $M$, Goldblatt $D$ \& Roos $D$ (2002). Prenatal diagnosis in two families with autosomal, p47(phox)deficient chronic granulomatous disease due to a novel point mutation in NCF1. Prenatal Diagnosis, 22: 235-240.

24. Baehner RL, Millar-Groff S \& Bringas P (1999). Developmental expression of NADPH phagocytic oxidase components in mouse embryos. Pediatric Research, 46: 152-157.

25. Banerjee R, Anguita J, Roos D \& Fikrig E (2000). Cutting edge: infection by the agent of human granulocytic ehrlichiosis prevents the respiratory burst by down-regulating gp91phox. Journal of $I m$ munology, 164: 3946-3949.

26. Bayraktutan U, Blayney L \& Shah AM (2000). Molecular characterization and localization of the NAD(P)H oxidase components gp91phox and p22-phox in endothelial cells. Arteriosclerosis, Thrombosis and Vascular Biology, 20: 1903-1911.

27. Cobbs S, Malech HL, Leto TL, Freeman SM, Blaese RM, Gallin JI \& Lomax KJ (1992). Retroviral expression of recombinant p47phox protein by Epstein-Barr virus-transformed B lymphocytes from a 
patient with autosomal chronic granulomatous disease. Blood, 79: 1829-1835.

28. Gorlach A, Brandes RP, Nguyen K, Amidi M, Dehghani F \& Busse R (2000). A gp91phox containing NADPH oxidase selectively expressed in endothelial cells is a major source of oxygen radical generation in the arterial wall. Circulation Research, 87: 26-32.

29. Rouzaut A, Lopez-Moratalla N \& de Miguel C (2000). Differential gene expression in the activation and maturation of human monocytes. Archives of Biochemistry and Biophysics, 374: 153-160.

30. Patiño PJ, Perez JE, Lopez JA, Condino-Neto A, Grumach AS, Botero JH, Curnutte JT \& Garcia de Olarte D (1999). Molecular analysis of chronic granulomatous disease caused by defects in gp91-phox. Human Mutation, 13: 29-37.

31. Ochs HD \& Igo RP (1973). The NBT slide test: a simple screening method for detecting chronic granulomatous disease and female carriers. Journal of Pediatrics, 83: 77-82.

32. Boyum A (1968). Isolation of mononuclear cells and granulocytes from human blood. Scandinavian Journal of Clinical and Laboratory Investigation, 21 (Suppl 97): 1-77.

33. Condino-Neto A, Muscara MN, Grumach AS, Carneiro-Sampaio MMS \& de Nucci G (1993). Neutrophils and mononuclear cells from patients with chronic granulomatous disease release nitric oxide. British Journal of Clinical Pharmacology, 35: 485-490.

34. McCord J \& Fridovich I (1969). Superoxide dismutase: An enzymatic function for erythrocuprein (hemocuprein). Journal of Biological Chemistry, 244: 6044-6055

35. Condino-Neto A, Muscara MN, Grumach AS, Bellinati-Pires R, Brandao AC, Carneiro-Sampaio MMS \& de Nucci G (1996). The effect of recombinant human interferon-gamma therapy on neutrophil and mononuclear cell nitric oxide release from patients with chronic granulomatous disease. Journal of Interferon and Cytokine Research, 16: 357-364.

36. Volkman DJ, Buescher ES, Gallin JI \& Fauci AS (1984). B cell lines as models for inherited phagocytic diseases: superoxide generation in chronic granulomatous disease and granules in Chediak-Higashi syndrome. Journal of Immunology, 133: 3006-3009.

37. Nilsson K, Klein G, Henle W \& Henle G (1971). The establishment of lymphoblastoid cell lines from adult and fetal human lymphoid tissue and its dependence on EBV. International Journal of Cancer, 8: 443-450.

38. Ginsburg D, Handin RI, Bonthron DT, Donlon TA, Bruns GAP, Latt SA \& Orkin SH (1985). Human von Willebrand factor: Isolation of complementary DNA clones and chromosomal location. Science, 228: 1401-1406.

39. Subrahmanyam YVBK, Baskaran N, Newburger PE \& Weissman SM (1999). A modified method for the display of 3 '-end restriciton fragments of cDNAs: Molecular profiling of gene expression in neutrophils. Methods in Enzymology, 303: 272-297. 